\title{
In what sense is the Louw/Nida dictionary authoritative?
}

\author{
Willem S Vorster \\ University of South Africa
}

\begin{abstract}
In what sense is the Louw/Nida dictionary authoritative?

This essay deals with four factors which make the Louw/Nida dictionary authoritative. These include the presentation of lexical meanings in semantic domains, the definition of meanings, the distinction that is made between meaning and reference, and the layout of the dictionary. All factors are discussed critically and examples of where the dictionary fails are given.
\end{abstract}

The Greek-English lexicon of the New Testament based on semantic domains, edited by $\mathrm{J} \mathrm{P}$ Louw \& $\mathrm{E} \mathrm{A} N \mathrm{Nida}$, and hereafter referred to as $L \& N$, has received a remarkably positive reception by the scholarly world until now. According to Reese (1988:150): '[T]he publication of this attractively presented lexicon will force the scholarly guild to pay attention to the linguistic methodology underlying this revolutionary achievement'. In a similarly positive review, Silva (1989:165) maintains: "[T]his work has to be regarded as a prodigious step forward in the field of lexicography generally, and in the study of NT vocabulary specifically' (see also Boers 1989; Botha 1989; Elliott 1988; Lategan 1986; Snyman 1988). I am also of the opinion that it is a major achievement in lexicographical studies of the vocabulary of the Greek New Testament. The dictionary offers a new approach to lexical semantics in this field, and it is in many ways totally different from existing dictionaries on the New Testament. This gives rise to the question of how authoritative this lexicon is. This essay was prepared for a symposium on the Louw/Nida wordbook at the annual meeting of
the Society of Biblical Literature in New Orleans, November 1990 . 
In the introduction to $L \& N$ the compilers assert that:

The principal reason for a new type of Greek New Testament lexicon is the inadequacy of most existing dictionaries, which for the most part are limited in indicating meanings, since they depend principally on a series of glosses.

\section{(Louw \& Nida 1988:viii)}

Rather than asking whether these inadequacies have been overcome in this new dictionary, I decided to address the problem of the authority of $L \& N$ (see Barnhart - 1980). By this I mean whether the scholarly world can rely on this dictionary as an 'authority' for the lexical meanings of the words used in the Greek New Testament. 'Authority' is used here in the sense of 'the power or right to control, judge or prohibit the actions of others' (Collins $1986 \mathrm{~s} \mathrm{v}$ ). It is apparent that there are aspects on which this dictionary cannot be regarded as authoritative since, it was not designed to give information on such aspects. It is, for example, not authoritative on etymology, morphology, pronunciation, syntax, the lexical meaning of each occurrence of a particular word in the New Testament, and the meaning of the words discussed in their usage outside the New Testament, to mention but a few things. $L \& N$ is a semantic dictionary dealing with the lexical meanings of the Greek words in the New Testament. It can therefore only be authoritative with regard to the meaning of words in the New Testament. The question of authority will therefore be addressed in this respect.

It should be kept in mind that $L \& N$ was developed primarily for use by translators. This explains the many annotations relating to translation included in the dictionary. This does not, however, imply that the dictionary cannot be an authority or a help for other users such as students, exegetes, theologians and all other persons interested in the meaning of New Testament words. On the contrary. The dictionary gives a comprehensive treatment of approximately 25000 meanings of some 5000 words which are used in the New Testament. I shall limit my discussion of the question of the authority of $L \& N$ to lexical semantics only.

According to Louw (1979:109): 'The purpose of the Wordbook is to provide accurate and practical guidance in determining satisfactory equivalences for the Greek NT vocabulary'. This means that translators and exegetes are provided with 'clear descriptions of areas of meaning of single words, set phrases and idioms', and that indications are given of 'how equivalences of meaning may be satisfactorily expressed in other languages' (Louw 1979:109). How successful is $L \& N$ in this 
regard? This question will be approached from different perspectives. Let us first deal with the arrangement of meaning in the dictionary.

The main difference between $L \& N$ and other bilingual dictionaries on the New Testament is that in $L \& N$ the focus is on the related meanings of different words, and not on the different meanings for which a particular word is used in the New Testament. That is why the many meanings for which Greek words are used in the New Testament are organised into ninety-three semantic areas or domains. This is perhaps the most innovative aspect of the dictionary since it is the first time in history that an attempt has been made to arrange the different meanings of the complete New Testament vocabulary into semantic domains.

The idea of the arrangement of meaning into semantic domains is nothing novel (see Geeraerts 1986:67-148). What is new is the arrangement of the different meanings of Greek New Testament terms into semantic fields. The question we have to ask is what this arrangement is based on, and what makes the arrangement of $L \& N$ authoritative.

The compilers of the dictionary assert that the semantic domains of $L \& N$ reflect the classification of words into semantic areas on the ground of three basic kinds of semantic components, namely shared or common components, distinctive or diagnostic components, and supplementary components (see Louw 1979:109). According to their view (see Louw 1979:108f; also Louw \& Nida 1988:ix) these domains do not follow a system of classification based on, for example, logicophilosophical categories as in the case of Roget or the classification proposed by Friedrich (1973). The assumption is that $L \& N$ 's classification reflects the semantic structure of the Greek of the New Testament. Louw (1979:109) even claims that their classification is based on an 'emic' approach, 'that is to say, an assignment of meanings as they would have been classified by native speakers of Koine Greek'. In accordance with the view of the ancients who regarded 'fire' as one of the four basic elements, $\pi \hat{p}$, for example, is classified as a substance and not as a process, it is argued (see also Louw \& Nida 1988:xiv).

There are a few basic insights, and perhaps even problems, which have to be dealt with before we continue our discussion of the authority of the dictionary in this regard. First of all it is necessary to decide what the compilers of the dictionary did when the classification of the different meanings of the Greek New Testament vocabulary was made. Did they discover, analyse or find the semantic domains inherent in the vocabulary, or did they create them? 
It is well known that the terms 'emic' and 'etic' were first used by anthropologists in the description of behaviour (see Pike 1966). These terms represent two standpoints 'which lead to results which shade into one another' (Pike 1966:152). While the etic (coined from phonetic) standpoint studies behaviour and language from outside a system, the emic (from phonemic) standpoint studies the system from inside. There is a vast difference between the two approaches, especially with regard to the Greek of the New Testament, although there also is no reason for a dichotomy between the two approaches. The one is dependent upon the other.

Pike (1966:153f) gives a very useful survey of the most important characteristics of the two standpoints. It becomes clear that, if we apply these characteristics to the study of the language of the New Testament, one can hardly speak of studying the Greek vocabulary solely from an emic point of view. While the emic structure of a system, for example, has to be discovered, the etic structure is created, Pike (1966:153) argues. With regard to New Testament Greek one will have to assume two things, if one holds the view that it is analysed emically. The first assumption is that there is an inherent system in the language, and the second is that it is possible to discover it. Both these views are problematic. Let us deal with the latter first.

We study the Greek of the New Testament, which is part of Hellenistic Greek of that era, mainly from an etic point of view. Due to the lack of native speakers and the lack of exact information on the spoken language of the writers of the New Testament documents, there is no reason for any scholar to claim that the language of these documents is studied or described from inside, that is from the standpoint of a native speaker of that language (see also Ossege 1975:79). The problem is that we know so little about the 'language of the New Testament'. It is only for the sake of convenience that we speak of 'New Testament Greek'. The documents were written by different authors, in different parts of the Near East and Asia, at different times and in different circumstances. Some of the documents were written by bilingual authors whose second language was Greek, others by authors who had a good command of the language. In what sense can one then speak of the semantic structure of the Greek of the New Testament? These factors contribute to the difficulties involved in having an emic view of the 'language' of the New Testament. It is more than difficult to discover the cultural key - that is, the knowledge of the emic system - of the Greek of the New Testament. What we actually do is to construe the cultural key by studying the language from outside. This, in my opinion, also applies both to the classification of the semantic structure of the New Testament vocabulary into semantic domains by Louw and Nida, and their definition of lexical meanings of this vocabulary. The semantic domains were created rather than discovered, and so was the definition of meanings with the help 
of componential analysis. Let us elaborate.

The compilers of $L \& N$ correctly reject the structure proposed by Friedrich and have convincingly drawn attention to problems involved in the structuring of the lexical meanings of the New Testament vocabulary in existing dictionaries (see Louw 1985b:53ff). But what about their own structure? Are their domains built on that inherent in the semantic structure of the New Testament vocabulary, as they presume?

The domains of $L \& N$ obviously reflect the theory on which the dictionary is based. In the first place they reflect the idea that words can be divided into four main categories namely - events, objects, abstracts and discourse referentials. Furthermore, they reflect the idea that the meaning of words can be determined by an analysis of their components, and that this excludes the use of encyclopaedic knowledge, to mention only thwo further aspects. There are more. This has resulted in a very impressive classification of the different meanings of related words into ninety-three main domains of meaning. One should, however, not forget that the three mentioned principles of classification form the basis of this classification. In fact, they explain what the compilers discovered and how they succeeded in creating their classification. Whether these principles comply with the way in which first-century Greek-speaking Christians used lexical meanings is another matter.

Some of the domains may certainly overlap with the way native speakers may have understood the relation between related meanings. This is particularly true with regard to semantic domains which are easy to recognise - such as plants, animals, foods, body and parts of the body and kinship terms. There are, however, numerous fields which are not so clear. A good example is domain 25, 'Attitudes

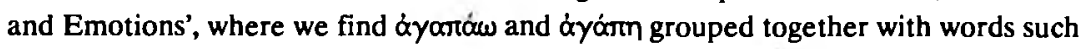

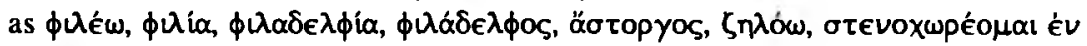

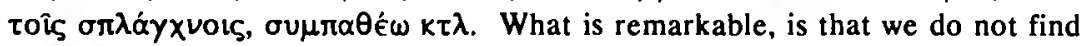
$\mu$ ló̇ $\omega$ here. We find $\mu$ loé $\omega$ under the subdomain 'Hate, Hateful' with words such

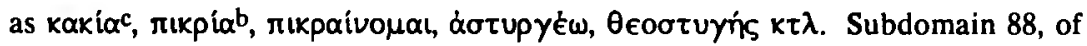
which these words form part, concerns 'Moral and Ethical Qualities and Related Behavior'. This is a matter of interpretation. If 'hate' belongs to this domain, does 'love' not also belong here, and why are rioúolos and related words not included under domain 88 (see Malina 1987)? How would native speakers have understood these terms? Another example might help us a little further.

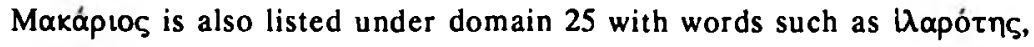

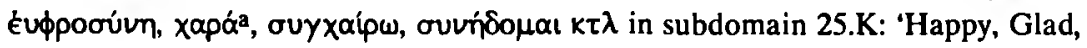
Joyful'. There are, however, interpreters who argue that the 'beatitudes' should be 
read as apocalyptic blessings (see Guelich 1976). These might argue that the meaning of $\mu$ axóplo̧ would not be 'pertaining to being happy, with the implication of enjoying favorable circumstances', but that the word should be placed under domain 53, 'Religious Activities'- that is, 'pertaining to being blessed by God'. Such examples can be multiplied. One soon realises that semantic domains can easily be structured in different ways depending on what one sees as the distinguishing component of meaning (see also Geeraerts 1986:112ff). A good example would be É $\sigma \theta$ iw. According to $L \& N$ the word means 'to consume food, usually solids, but also liquids'. The last part of the definition is included to accommodate the use of $\tau$ irs

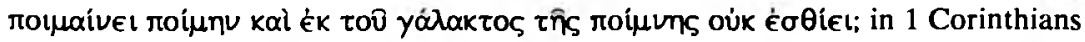
9:7. To my mind the use of the preposition Ek with the verb has to be taken seriously. I think that EoOiw means 'to consume food' and that it is used in the New Testament for that meaning only, also in 1 Corinthians 9:7. It is furthermore used as

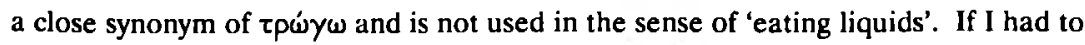
structure the subdomain, I would have placed $\dot{\epsilon} \sigma \dot{\theta} \omega$ first and then $\tau \rho \dot{\omega} \gamma \omega$ and so on, in this order. This is just to show that the structuring of the domains is determined by one's interpretation of the lexical meaning of words. Both the structure and the definition of meanings are ascribed, obviously normally on good grounds, not discovered. Let us go a little further.

'[W]ords are rooted in social systems; they realize meanings from social systems' (Malina 1987:358). To classify the meaning of Greek New Testament words into semantic domains presupposes the ability to reconstruct original contexts of communication in the first-century Mediterranean world. This is an almost impossible task. The most we can do is to construct possible cross-cultural contexts of understanding.

The idea that there is an inherent semantic structure in language, which has to be discovered and described, is equally problematic. It is based on structural semantics, which was in vogue from 1930-1975. One of the main problems is that too little distinction is made between knowledge of language and knowledge of the world. Structural semantics presupposes that language has its own semantic structure - which has nothing to do with encyclopaedic knowledge. In the words of Louw (1985a:80): 'It is ... important that we should add strictly semantic dictionaries to our list of different types of dictionaries'. This view has been rejected as illusionary since it is argued that the difference between encyclopaedic and 'pure' semantic knowledge does not exist (see Geeraerts 1986:187).

From the perspective of cognitive semantics, 'universals', such as objects, events, and abstracts, are not regarded as common structures or elements of language. They are regarded as common strategies to classify experience. Language is furthermore 
seen as part and parcel of cultural contexts (see Geeraerts 1986:198f). 'Semantic structures are taken to be nothing other than conceptualizations shaped for symbolic purposes according to the dictates of linguistic convention' (Langacker as quoted by Geeraerts 1986:211).

The point I wish to make is that the compilers of $L \& N$ are responsible, on both emic and etic considerations, for their classification of related meanings into domains and subdomains. They did not discover these categories in the semantic structure of the Greek New Testament vocabulary. They created these domains in the light of their analysis of the related meanings of words. Once one realises this, the dictionary can be used in an interactive fashion. If one knows that the domains of $L \& N$ are possible ways of dealing with related meanings in the New Testament, the user can start using the material critically. This is exactly what makes $L \& N$ authoritative. It is not because the last word has been said about the relation between related meanings of different words in the New Testament that this lexicon is an authority that has to be followed. It is because the dictionary enables the user to see a particular word within the context of other words which are possibly related that it is to be regarded as an authority. In the words of Louw and Nida (1988:x): 'The primary value of a lexicon based upon semantic domains is that it forces the reader to recognize some of the subtle distinctions which exist between lexical items whose meanings are closely related and which in certain contexts overlap'.

A second factor which makes $L \& N$ authoritative is the definition of the meaning of individual words. In this respect, the dictionary is totally different from all existing bilingual dictionaries on the vocabulary of the New Testament.

The description of meaning by way of definition instead of in glosses and translational equivalents makes this dictionary unique. The definitions are the result of the analysis of the components of the lexical meaning of each individual word. In most cases the definitions reflect the diagnostic components of the particular meaning. In this manner the different meanings are identified and made more precise. The advantage of definitions of meaning over translational equivalents is obvious. While translational equivalents are approximate presentations of the lexical meaning of a word in the source language, definitions are supposed to be more precise. ,

Componential analysis is not an unknown method of analysing the lexical meanings of words. The advantage of defining meaning in this way is that the focus is on those components that distinguish the meaning of particular words from one 
another. It also helps to see which components are shared by words with related meanings and which are supplementary. Ideally, this is one of the best ways of dealing with meaning. There are, however, also disadvantages in this approach to the analysis of meaning.

As we have seen above, with regard to domains, it appears an illusion that semantic fields can be clearly marked in accordance with an inherent semantic structure. Since semantic domains are fuzzy, and since the boundaries of lexical meanings are also fuzzy, one can never say with certainty that a particular feature is the diagnostic component of the lexical meaning of a particular word (see also Geeraerts 1986:112ff). Meanings overlap and are dependent on subtle distinctions and on connotative and associative elements, and can therefore never be analysed in a mechanical or machine-like manner. That, perhaps more than anything else, explains why some of the definitions of $L \& N$ are better than others, and why some are totally inadequate. A few examples may illustrate the point.

I would regard the definition of the meaning of $\theta u \mu$ iáw as 'to burn aromatic

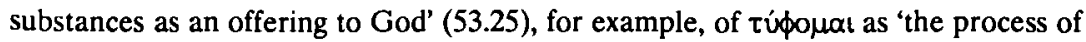
burning slowly, with accompanying smoke and relatively little glow'(14.64), of $\sigma \in t \sigma \mu o ́ s$ as 'a sudden and severe movement of the earth' (14.87), and all the meanings defined in 15 as adequate and good definitions of the lexical meaning of the particular words. Others, however, are unconvincing and inadequate for different reasons. The definition of $\beta \alpha \pi \tau$ เ $\sigma \tau$ n' $(53.42)$ as 'one who baptizes' does not explain the meaning of the word. What is the difference between the lexical

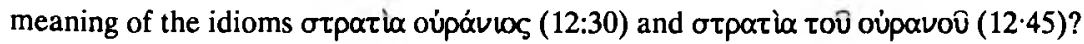
I find the definitions 'a large group or throng of angels' (12:30) and 'the stars of heaven as symbols of various supernatural powers' (12:45) unconvincing. What does it mean to be 'free' as in the case of é $\lambda \epsilon u \theta \epsilon \rho i \alpha$ ('the state of being free') and

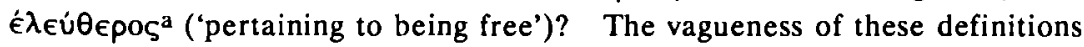
becomes a problem when one compares them with é $\lambda \in \dot{U} \theta \epsilon \rho \circ \zeta^{b}$ (87.84), 'pertaining to a person who is not a slave, either one who has never been a slave or one who was a slave formerly but is no longer'.

The fact that definitions of meaning are omitted in some cases also causes

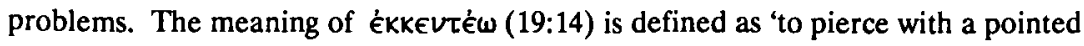
instrument', while the meaning of viorw is not defined. Both are then translated by 'to pierce'. In the case of the latter there is an annotation - reading: 'normally not

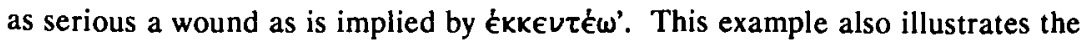
problem of defining the meaning of words from the outside. Although the compilers hold the view that there is no such thing as words having completely the same meaning (Louw \& Nida 1988:xv), they are unable to distinguish the subtle differen- 
ces between these words that are used by the same author in close connection (see, however, 19.18 and 19.19). The entries under 53.4-7 also illustrate that it is almost impossible to define close synonyms in the New Testament with the help of componential analysis. We just do not have the competence to distinguish the subtle differences in the meanings of these words.

The compilers are moreover, not always consistent in their definitions of lexical meaning. A good example is the definition of words referring to specific festivals (see 51.5-12). In some cases even the date of the festival is given, while in others it is not. The same applies to words for coins in 6.76-82. In most cases it is said whether the coins were Roman or Greek. Only in the case of $\lambda \in \pi \tau o$ ond otatip is this not done. Are these features not diagnostic for outsiders as well in these two cases?

Some definitions display the convictions and beliefs of the compilers more than others. One such case is the entry on $\theta \in o ́ s ~(12.1)$ which certainly contains much more than semantic information, especially when it comes to matters such as the patropassion heresy! Is the definition 'a title with Messianic implications used by Jesus concerning himself', a definition of the diagnostic components of the words

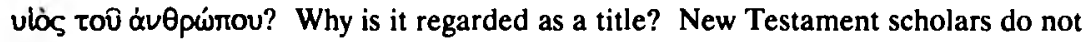
agree about this. Why Messianic? The same applies to the annotation (?) in brackets after $\pi v \in \hat{U} \mu \alpha \alpha$ (12.18), which reads: 'a title for the third person of the Trinity ...'. Does this annotation define the meaning of the word? And if so, is it from an emic point of view?

The definitions of the meanings of $\alpha \lambda \eta \theta$ 's, 'pertaining to being in accordance with historical fact', and of a $\alpha \hat{n} \theta \in \omega$, 'the content of that which is true and thus in accordance with what actually happened', reflect a positivist perception of truth. It is doubtful whether these definitions reflect the lexical meanings of the words in the New Testament.

There are other definitions which are also debatable, but the above examples will suffice.

In spite of the problems I have discussed with regard to the definition of meaning in some entries, one should not get the impression that $L \& N$ is not generally speaking authoritative in this respect. I would like to underscore the fact that the description of meaning by way of definitions is far more appropriate than the giving of translational equivalents. 
A clear distinction is furthermore made between meaning and reference by the compilers of $L \& N$ (Louw and Nida 1988:xvii). In this respect, too, the lexicon is authoritative. There is a tremendous difference between what a word means and what it refers to, something of which scholars are not always aware. $L \& N$ is very helpful in this regard. In some cases, however, it is not clear whether certain definitions in $L \& N$ are given in terms of meaning or reference (see 11.59-64, also 11.66 and 53.52). Let us consider a few examples.

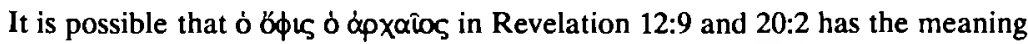
'devil'. The term clearly refers to the 'devil', and it is probable that oo $\phi$ cs could have acquired this meaning in Jewish Christian circles. Just as ö $\phi 1 \varsigma^{b}$, 'evil person' is a figurative extension, the meaning 'devil' would also be a figurative extension. References become meanings of words through convention. Another, perhaps even clearer, case would be ó $\phi \theta \alpha \lambda \mu d \varsigma$ nounpó $\varsigma^{\mathrm{a}, \mathrm{b}}$. Both meanings are regarded as idioms in $L \& N$. They have been defined as 'a feeling of jealousy and resentment because of what someone else has or does' (88.165), and 'to be stingy'. Nowhere does one, however, find a reference to the belief in an Evil Eye which was common at the time of the New Testament in the Mediterranean world, as J H Elliott (1988) has convincingly shown.

The inclusion of oúpavó $\varsigma^{c}$ (12.16) under 'Supernatural Beings' is furthermore understandable, but nevertheless problematic. Instead of giving a definition of the meaning of the word, an annotation explains the term. It reads 'a reference to God based on the Jewish tendency to avoid using the name or direct term for God'. If oúpavós is used, like שמים, as a replacement for the name of God, one would first of all expect the term under 'Names of Persons and Places'(93).

Since there are many annotations included in $L \& N$ for the sake of the translator, it would have been of help had there been more remarks about reference in cases where it is possible to determine what words refer to.

A final factor which makes this dictionary authoritative is its layout, since it compels the user to consider thoroughly whether a particular meaning is applicable. It therefore has an educational function.

Users of lexica often tend to think that the purpose of bilingual lexica is to provide the user with the meaning of a word in a particular context. It is often not realised that a lexicon is only an aid for the user to determine the meaning of a particular word in a particular context. It is the user, not the lexicon, or the compilers of the lexicon, who has to determine the meaning of a word in use. The 
way in which $L \& N$ presents information on the lexical meaning of New Testament words forces the user to make use of the information in a creative way.

Although $L \& N$ gives a complete survey of all the meanings for which the different words in the New Testament are used, it is not complete with regard to each case where a particular meaning is applicable. This simply means that the user has to make full use of the information provided in the dictionary. If a particular case is not mentioned in the reference index, the user has to consult the other indices. Having decided that a particular word mentioned under a Greek entry might be applicable, both the definition of that meaning and the definition of other related meanings in its immediate area have to be consulted. This is the only way to be relatively sure that a chosen meaning is applicable in a particular context.

Instead of going through the list of different meanings of a particular Greek word, as they normally occur in an alphabetically arranged dictionary, the user is introduced the semantic area of related meanings of different words. This has the advantage that, in addition to the different meanings of the same word, the user also sees the related meanings of different terms in the same semantic domain. Since meaning is also mostly defined and not presented in the form of glosses or translational equivalents, the user has to decide actively, with the help of semantic information provided by the dictionary, whether a particular choice is applicable.

I have discussed four factors which make $L \& N$ an authority on lexical meanings of the New Testament vocabulary. There are others. I am thinking of the importance of figurative extensions of meaning, the treatment of meanings of word groups and especially of idioms. The fact that idioms are listed and treated makes $L \& N$ unique. Space does not allow me to go into these factors further. Enough has been said to indicate that there are good reasons for this dictionary to be regarded as authoritative in different aspects and on different grounds. The publication is a milestone in the history of New Testament lexicography.

\section{Works cited}

Barnhart, C L 1980. What makes a dictionary authoritative, in Zgusta, L (ed), Theory and methord in lexicography: Western and non-Western perspectives, 33-42. Columbia: Hornbeam Press. 
Boers, H 1989. Review of Greek-English lexicon of the New Testament based on semantic domains, 2 vols. Edited by Johannes P Louw and Eugene A Nida. New York: UBS. $J B L$ 108, 705-707.

Botha, J 1989. Die Louw \& Nida-woordeboek: 'n Kragtige nuwe hulpmiddel vir die eksegeet, prediker en Bybelvertaler. In die Skriflig 23, 1-23.

Collins paperback English dictionary, The 1986. London: Collins.

Elliott, J H 1988. The fear of the leer: The evil eye from the Bible to Li'l Abner. Foundations \& Facets Forum 4, 42-71.

Elliott, J K 1989. Review of Johannes P Louw and Eugene A Nida (eds), GreekEnglish lexicon of the New Testament based on semantic domains, 2 vols. New York: UBS. NT 31, 379-380.

Friedrich, G 1973. Das bisher noch fehlende Begriffslexikon zum Neuen Testament. NTS 19,127-152.

Geeraerts, D 1986. Woordbetekenis: Een overzicht van de lexicale semantiek Leuven: Acco.

Guelich, R A 1976. The Matthean beatitudes: 'Entrance-requirements' or eschatological blessings? JBL 95, 415-434.

Lategan, B C 1988. Louw \& Nida: 'n Nuwe begrip in Griekse woordeboeke vir die Nuwe Tetsament. Scriptura 25, 48-51.

Louw, J P 1979. The Greek New Testament wordbook. BiTr 30, 108-117.

---(ed) 1985. Lexicography and translation: With special reference to Bible translation. Cape Town: Bible Society of South Africa.

--- 1985a. The present state of New Testament lexicography, in Louw 1985: 97. 117.

--- 1985b. What dictionaries are like, in Louw 1985: 53-81.

Louw, J P \& Nida, E A (eds) 1988. Greek-English lexicon of the New Testament based on semantic domains, 2 vols. New York: UBS.

Malina, B 1987. Wealth and poverty in the New Testament and its world. Interp. 41, 354-67.

Ossege, M 1975. Einige Aspekte zur Gliederung des neutestamentlichen Wort-

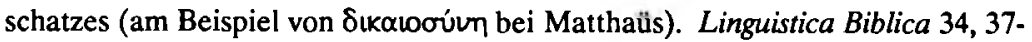
101.

Pike, K L 1966. Etic and emic standpoints for the description of behavior, in Smith, A G (ed), Communication and culture: Readings in the codes of human interaction, 152-163. New York: Holt, Rinehart and Winston.

Reese, J M 1988. Review of Johannes P Louw and Eugene A Nida (eds), GreekEnglish lexicon of the New Testament based on semantic domains, 2 vols. New York: UBS. BTB 18, 150-151. 
Silva, M 1989. Review of Johannes P Louw and Eugene A Nida (eds), GreekEnglish lexicon of the New Testament based on semantic domains, 2 vols. New York: UBS. WThJ 51, 163-167.

Snyman, A H 1988. Resensie van Louw, J P; Nida, E A; Smith, R B en Munson, $K$ A Greek-English lexicon of the New Testament based on semantic domains, 2 vols. New York: UBS. NGTT 29, 407-408. 